\title{
PEMODELAN ALIRAN AIR TANAH UNTUK SISTEM MANAJEMEN DAN PEMBANGUNAN DI KAWASAN PERKOTAAN KABUPATEN MAJENE, PROVINSI SULAWESI BARAT
}

\author{
Aji Marwadi ${ }^{1}$, Sugiarto Cokrowibowo ${ }^{2}$ dan Yusman ${ }^{1}$ \\ ${ }^{I}$ Program Studi Teknik Sipil, Universitas Sulawesi Barat \\ ${ }^{2}$ Program Studi Teknik Informatika, Universitas Sulawesi Barat \\ Email:aji.marwadi@unsulbar.ac.id
}

\begin{abstract}
ABSTRAK: Model air tanah yang digambarkan komputer merupakan sebuah representasi dari keadaan sebenarnya yang mewakilinya di lapangan, sehingga dapat berfungsi sebagai alat monitoring dan perkiraan suatu sistem aliran air tanah di masa depan. Tujuan dari penelitian ini adalah pemodelan aliran air tanah yang dapat mewakili kondisi sebenarnya yang terjadi di kawasan perkotaan Kabupaten Majene. Pemodelan dilakukan dengan cara numerik menggunakan Visual Modflow. Data masukan yang dibutuhkan adalah: korelasi data log bor/ geolistrik, batas (boundary) lokasi penelitian yang akan dimodelkan yaitu river boundary, yaitu pengukuran serta pengamatan kondisi sungai, data imbuhan air tanah (infiltrasi) diperoleh dengan menggunakan neraca air tanah dari olahan data curah hujan dan suhu udara, pengukuran tinggi muka air tanah sebagai penentuan alat validasi/kalibrasi model untuk mendekati kondisi nyata di lapangan. Hasil dari penelitian ini secara kuantitatif berupa model aliran air tanah, sistem akuifer tersusun atas lapisan akuifer semi tertekan yang pada bagian atasnya dilapisi oleh lapisan lempung yang berupa sisipan pada berbagai daerah tertentu. Akuifer pertama tersusun atas endapan pasir yang terdapat sisipan material lempung $(\mathrm{K}=40 \mathrm{~mm} / \mathrm{hari})$, Akuifer kedua tersusun atas endapan pasir sedang ke halus $(\mathrm{K}=25$ $\mathrm{m} /$ hari) dan akuifer ketiga berupa pasir, gamping dan kerikil $(\mathrm{K}=25-50 \mathrm{~m} / \mathrm{hari})$ yang terhubung dengan dua akuifer sebelumnya. Lokasi penelitian memiliki kecenderungan arah aliran air tanah Utara-Selatan menuju ke arah pantai dengan nilai rata-rata imbuhan air tanah sebesar $100 \mathrm{~mm} /$ tahun.
\end{abstract}

Kata kunci: Air tanah, konduktivitas hidrolik

\section{GROUNDWATER FLOW MODELING FOR MANAGEMENT AND DEVELOPMENT SYSTEMS IN THE URBAN AREA OF MAJENE DISTRICT, WEST SULAWESI PROVINCE}

ABSTRACT: The computer-depicted groundwater model is a representation of the actual situation that represents it in the field, so that it can function as a monitoring and forecasting of a future groundwater flow system. The purpose of this study is to model groundwater flow that can represent the actual conditions that occur in the urban area of Majene Regency. The modeling is conducted by numerical method using Visual Modflow. The input data required are log bor / geoelectric data correlation, the boundary of the research location to be modeled, namely the river boundary, namely measurement and observation of river conditions, groundwater recharge data (infiltration) obtained by using groundwater balance from processed rainfall data. and air temperature, groundwater level measurement as a means of determining model validation / calibration to approach real conditions in the field. The results of this research, in quantitative, are in the form of a groundwater flow model, an aquifer system composed of a semi-stressed aquifer layer which is topped by a clay layer that filled in certain areas. The first aquifer is composed of sand sediment with clay material ( $K$ $=40 \mathrm{~mm} /$ day), the second aquifer is composed of medium to fine sand deposits ( $K=25 \mathrm{~m} /$ day) and the third aquifer is sand, limestone and gravel $(K=25-50 \mathrm{~m} /$ day) that connected to the previous two aquifers. The research location has a trend towards the north-south direction of groundwater flow towards the coast with an average groundwater recharge value of $100 \mathrm{~mm} / \mathrm{year}$.

Keywords: Groundwater, Hydraulic conductivity 


\section{PENDAHULUAN}

Air bersih merupakan sumber daya yang terbatas walaupun termasuk sumber daya yang terbarukan, karena hanya sedikit yaitu $2,4 \%$ dari total global water yang berada di permukaan bumi yang dapat diakses untuk dimanfaatkan (Wilopo, 2018). Air tanah biasanya digunakan untuk berbagai kepentingan baik untuk sumber air bersih rumah tangga, irigasi, industri, dan sebagainya. Kebutuhan air tanah akan semakin meningkat dengan diikuti kenaikan populasi penduduk untuk itu manajemen dan perlindungan dari air tanah sanggatlah penting untuk keberlangsungan hidup manusia (Rejekiningrum, 2010). Peningkatan urbanisasi mengakibatkan peningkatan kebutuhan air bersih sebagai kebutuhan primer sehingga berpotensi menurunkan kualitas pemukiman dalam pemanfaatan air.

Model aliran air tanah dapat membantu untuk menganalisis dari berbagai permasalahan tentang air tanah. Pemodelan numerik air tanah banyak dipakai dan dikembangkan untuk memahami sistem aliran air tanah (Lakshmi dan Narayanan, 2015), mengevaluasi setiap perubahan cadangan air tanah (Sallam, 2015), memprediksi akibat dari pengairan yang menggunakan air tanah (Hendrayana dan Putra, 2015) dan sebagai petunjuk dalam mengatur cadangan air (Barnett et al., 2012).

Model air tanah yang digambarkan komputer adalah sebuah representasi dari keadaan sebenarnya yang mewakilinya di lapangan, sehingga dapat berfungsi sebagai monitoring dan perkiraan suatu sistem aliran air tanah di masa depan. Simulasi dari pemodelan tersebut diharapkan dapat membantu dalam manajemen air tanah (Sahoo dan Jha, 2017).

Pertimbangan sistematis air tanah dalam pembangunan perkotaan dan penerapan sistem manajemen air tanah dapat berfungsi sebagai alat pengambilan keputusan bagi pihak perencana proyek dan lembaga pemerintah. Hal ini memungkinkan adaptasi berkelanjutan (sustainable) untuk masalah saat ini dan tuntutan masa depan (Sallam, 2015).

Selain itu, model air tanah semakin terintegrasi dengan model permukaan darat lainnya, perubahan iklim, precipitation- runoff, proses ekologi dan data aliran sungai dalam beberapa tahun terakhir. Semua upaya dalam pemodelan ini meningkatkan pemahaman tentang sistem air tanah yang bekerja, proses aliran air tanah, dan interaksi dengan komponen siklus air lainnya (Yao et al., 2015).

Model hasil kalibrasi terakhir akan dapat digunakan sebagai perhitungan kesetimbangan air tanah dan alat untuk mengetahui dampak perubahan kondisi air tanah, seperti dengan melakukan simulasi kebutuhan air tanah, intrusi air laut atau melacak penyebaran polutan di masa depan (Marwadi, 2018).

Area Studi

Lokasi penelitian berada dalam daerah administratif dari Kabupaten Majene, Provinsi Sulawesi Barat, Indonesia. Kabupaten ini sebagian besar daerahnya berada di pinggir pantai dengan panjang garis pantai yang memanjang dari Selatan ke Utara daerah tersebut adalah $125 \mathrm{Km}$. Studi penelitian dilakukan di wilayah perkotaan Kabupaten Majene Provinsi Sulawesi Barat, terletak di sisi selatan Kabupaten Majene dengan ketinggian berkisar 10 meter sampai dengan 30 meter dari permukaan laut $(m d p l)$. Area penelitian memiliki sebuah sungai yang mengalir pada pertengahan kota menuju pantai dan daerah dengan penduduk $1.675 \mathrm{jiwa} / \mathrm{km}^{2}$ (Gambar 1).

Kondisi Geologi

Pada tahun 1998 Bachri et al membuat suatu peta geologi regional lembar Majene dan pada bagian barat dari daerah Palopo dengan skala 1:250.000 dan kemudian dilengkapi peta tersebut dengan daerah lembar Mamuju, dari perpaduan peta regional tersebut dapat disimpulkan bahwa kabupaten Majene tersusun atas 7 satuan yaitu, Aluvium (Qa), Endapan Antar Gunung (Qphs), Napal Pambauang (Qpps), Batuan Terobosan (Tmps), Batuan Gunungapi Walimbong (Tmpv), Formasi Makale (Tomm) dan Formasi Mapi (Tmpm) (Sunarwan dan Firmansyah, 2016).

Daerah Sulawesi Barat terdapat dua lajur lipatan dan sesar naik, yaitu Lajur Lipatan dan sesar naik Kalosi dan Lajur Lipatan dan sesar naik Majene. Daerah lajur lipatan dan 


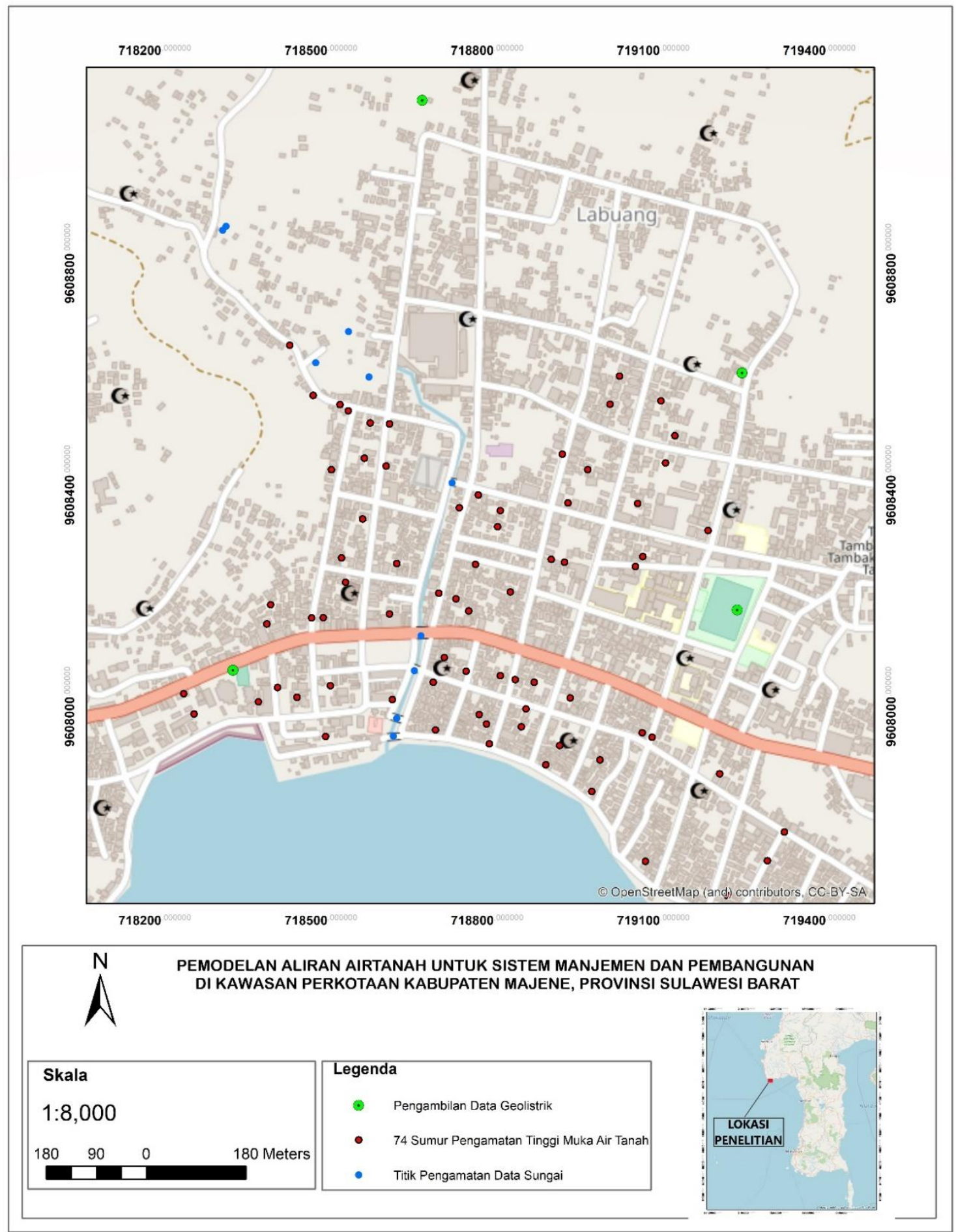

Gambar 1. Peta lokasi penelitian

sesar naik Majene ditempati oleh batuan sedimen dan batuan gunung api berumur Miosen Awal atau lebih muda, serta batu gamping yang terangkat berumur Pleistosen - Holosen (Bachri, 2012).

Kondisi Hidrogeologi
Jika ditinjau untuk air tanah dangkal dapat disimpulkan bahwa Kabupaten Majene tidak memiliki cadangan air tanah yang besar yang dapat dikategorikan sebagai CAT, pada Peta Cekungan Air Tanah Pulau Sulawesi pada Lembar VI dengan skala 1:250.000 Kabupaten Majene termasuk ke dalam wilayah Non-Cekungan Air Tanah. 


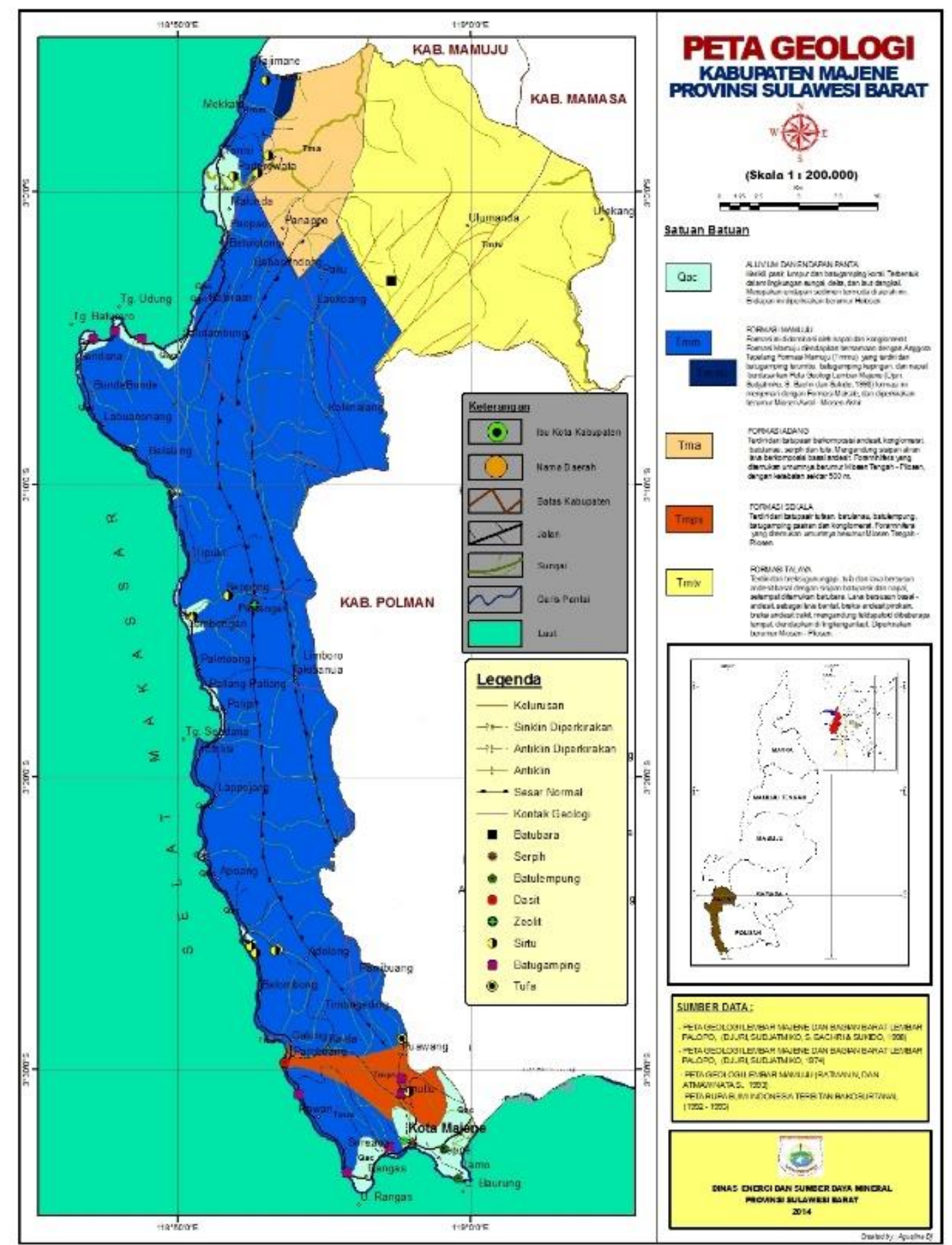

Gambar 2. Peta Geologi Kabupaten Majene.

Berdasarkan peta Hidrogeologi Regional Lembar Majene-Larampong dan Lembar Mamuju, Skala 1:250.000 (Sunarwan dan Firmansyah, 2016) secara lebih spesifik dapat diketahui kondisi hidrogeologi berdasarkan pada peta hidrogeologi regional, kemudian dapat diasumsikan Kabupaten Majene terdiri dari beberapa satuan Hidrogeologi, yaitu:
1) Daerah Air tanah Langka tanpa kandungan air tanah yang berarti.

2) Akuifer Produktif Kecil setempat berarti, yaitu pelapukan batuan pada daerah rendah mengandung air tanah dangkal dengan jumlah terbatas di beberapa lokasi dengan sebaran ketebalan dari rendah ke sangat rendah.

3) Akuifer Produktif Sedang, muka air tanah pada daerah ini tipis terhadap 
permukaan elevasi, keterdapatan lokasinya bersifat tertentu secara tidak merata.

4) Akuifer Produktif, sebuah akuifer yang dapat dikategorikan sebuah CAT, tetapi hanya berlokasi di daerah tertentu saja secara tidak merata.

5) Akuifer dengan Produktivitas Sedang.

Satuan hidrogeologi secara rinci pada keseluruhan diketahui (Sunarwan dan Firmansyah, 2016) wilayah Kecamatan Banggae dan Kecamatan Banggae Timur dikategorikan sebagai Akuifer Produktif Sedang.

\section{MATERI DAN METODE Pemodelan Air tanah}

Tujuan pemodelan harus dipersiapkan pada awal pemodelan sebagai pernyataan tentang bagaimana model dapat secara khusus berkontribusi pada keberhasilan penyelesaian atau kemajuan proyek secara keseluruhan, tujuan pemodelan harus digunakan secara teratur di seluruh proses pemodelan sebagai panduan bagaimana model harus dikonseptualisasikan, dirancang, dikalibrasi dan digunakan untuk prediksi dan analisis ketidakpastian (uncertainty) (Barnett et al., 2012). Pemodelan aliran air tanah memerlukan beberapa data parameter sebagai berikut (Gambar 3).

\section{Konseptual model akuifer}

Model konseptual (hidrogeologi) adalah representasi deskriptif dari sistem air tanah yang menggabungkan interpretasi kondisi geologi dan kondisi hidrologi (Anderson dan Woessner, 1992). Pembuatan konseptual dari data log bor dan/atau data geolistrik dengan penentuan geometri akuifer dilakukan dengan menentukan ketebalan serta sebaran akuifer dan melakukan klasifikasi terhadap sifat hidrolika dari batuan penyusun akuifer. Dalam pemodelan air tanah dibutuhkan data karakteristik akuifer untuk membedakan satu lapisan dengan lapisan lainnya dan sebaran dari setiap lapisan akuifer tersebut dengan menggunakan nilai konduktivitas hidraulika (K). Pada model ini dibedakan menjadi beberapa nilai konduktivitas hidraulika sesuai kebutuhan pemodelan dengan mengacu dari berbagai sumber data-data yang ada. Nilai konduktivitas hidraulika pada tiap unit diasumsikan memiliki nilai $\mathrm{kx}$ dan ky sama dan $\mathrm{kz}$ bernilai $10^{-1} \mathrm{kx}$ ataupun ky.

Nilai-nilai acuan dalam penentuan konduktivitas hidraulika (K) mengacu pada buku a practical guide to groundwater and solute transport modeling oleh Spitz dan Moreno, terbitan John Wiley \& Sons pada tahun 1996 dan sebuah laporan akhir eksplorasi air tanah di Pulau Dutungan Kabupaten Barru yang menggunakan data geolistrik untuk membandingkan dari jenis batuan yang berada di Pulau Sulawesi.

\section{Profil Geolistrik.}

Dari ke empat profil geolistrik yang diambil pada lokasi penelitian (Gambar 1) tersusun atas 4 lapisan yang dikategorikan secara umum berbeda dan pada lapisan pertama yang paling atas ditunjukkan dengan adanya celah-celah lapisan akuifer berupa sisipan.

Muka Air tanah.

Hasil dari pemodelan perhitungan software Visual Modflow adalah tinggi muka air tanah (dalam istilah visual modflow adalah head), berupa garis kontur tinggi muka airtanah yang menginformasikan head dari masing-masing grid yang dibuat pada model konseptual sebelum dilakukan running process jika ingin melakukan sebuah simulasi dampak dari perubahan lingkungan yang terjadi.

Sehingga pada proses kalibrasi dan validasi diperlukan tinggi muka air tanah real yang berada pada lokasi penelitian sebagai data kontrol. Beberapa tinggi muka air tanah yang akan digunakan sebagai alat kalibrasi diperoleh dengan melakukan interpolasi terhadap tinggi muka air tanah yang diukur pada sumur-sumur pengamatan di lokasi penelitian (Gambar 5). Kemudian untuk menentukan ketinggian muka air tanah (head) pada model diperlukan sebuah ketinggian yang akan menjadi dasar nilai ukuran ketinggian pada model yang akan diterapkan yaitu elevasi permukaan (surface-ground). Elevasi permukaan diperoleh dari DEMNAS, badan informasi geospatial yang merupakan data TIF yang memuat informasi data elevasi suatu wilayah. 
JURNAL ILMIAH TEKNIK SIPIL·A SCIENTIFIC JOURNAL OF CIVIL ENGINEERING・Vol. 25 No. 1 Januari $\quad$ ISSN: 1411-1292

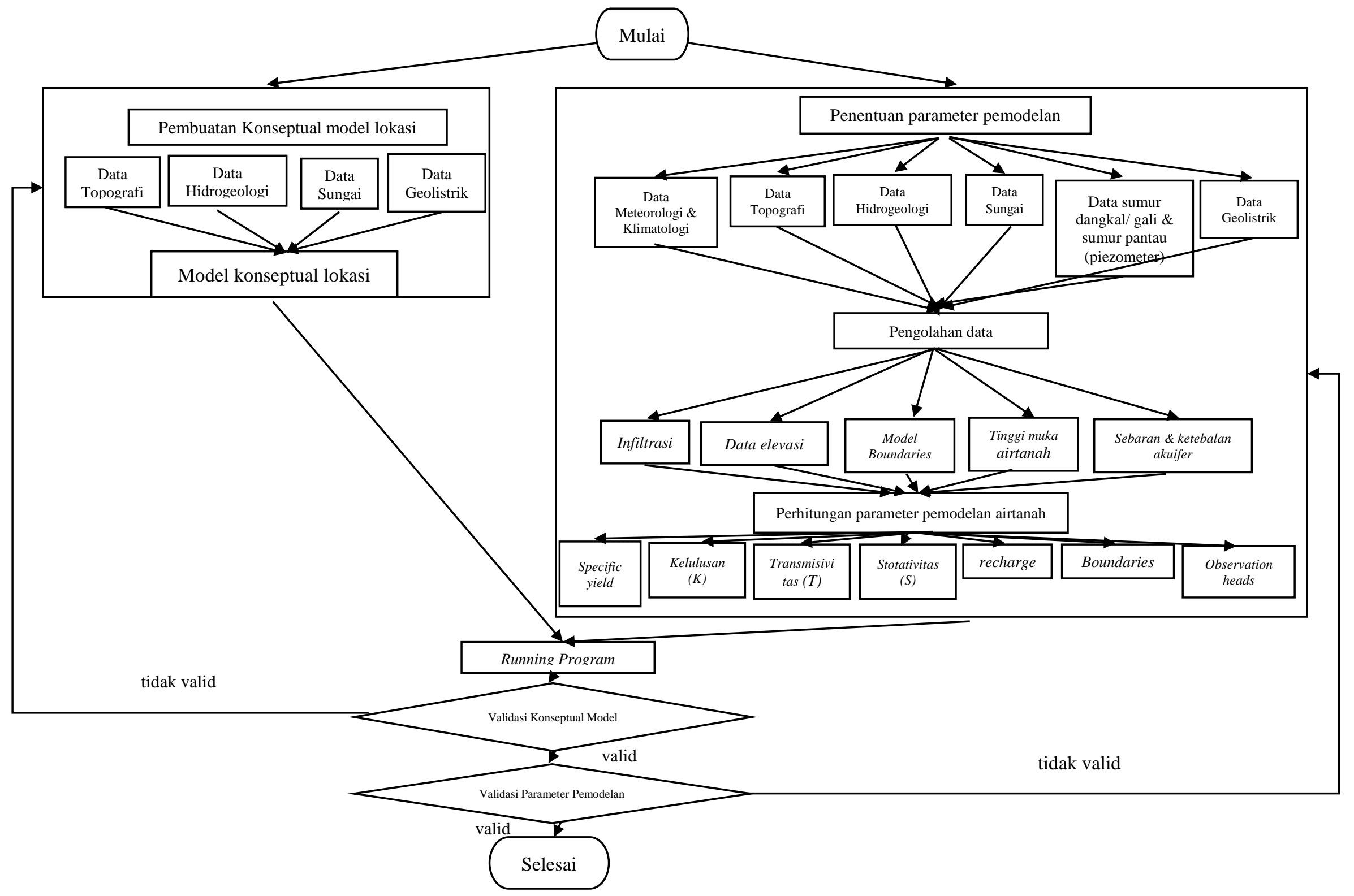

Gambar 3. Metode Penelitian 
a) Lokasi 1

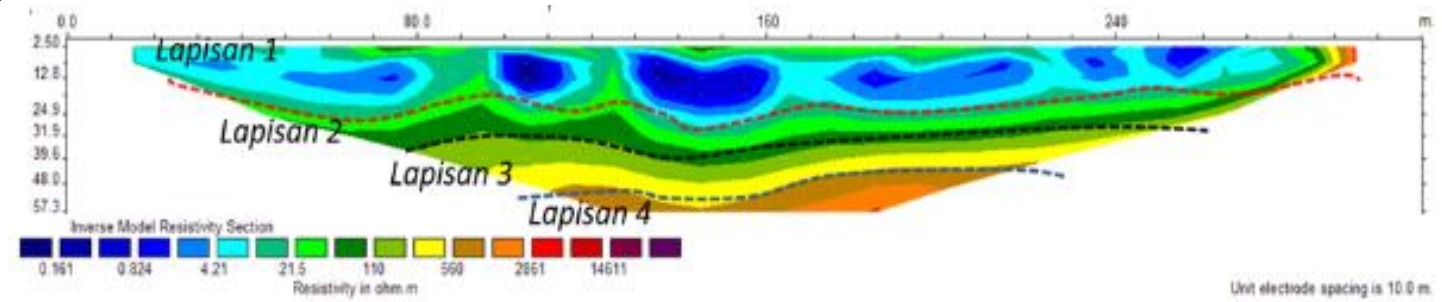

b) Lokasi 2

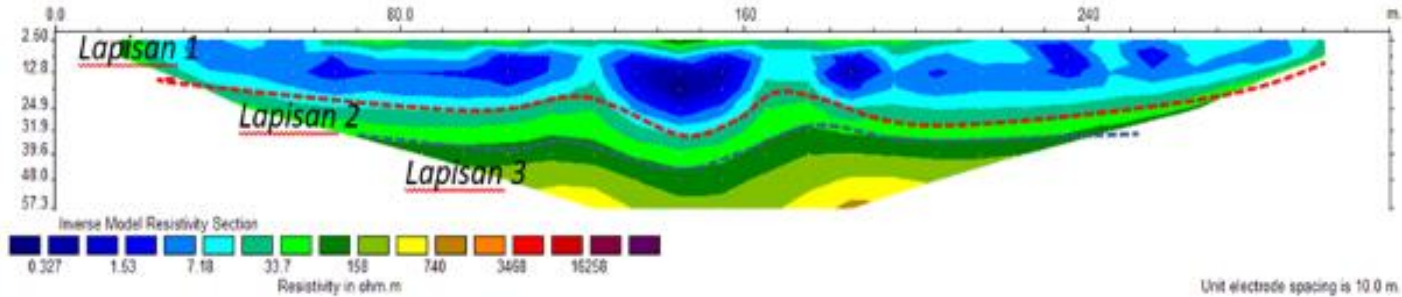

c) Lokasi 3

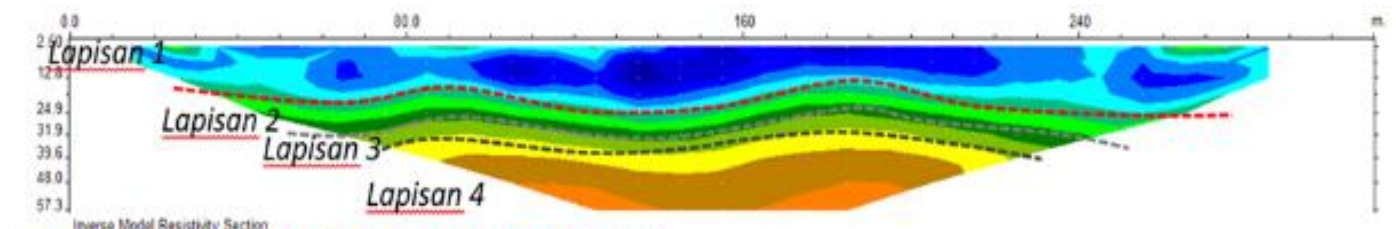

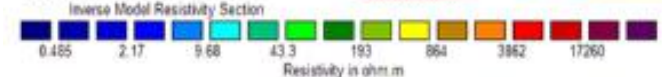

d) Lokasi 4

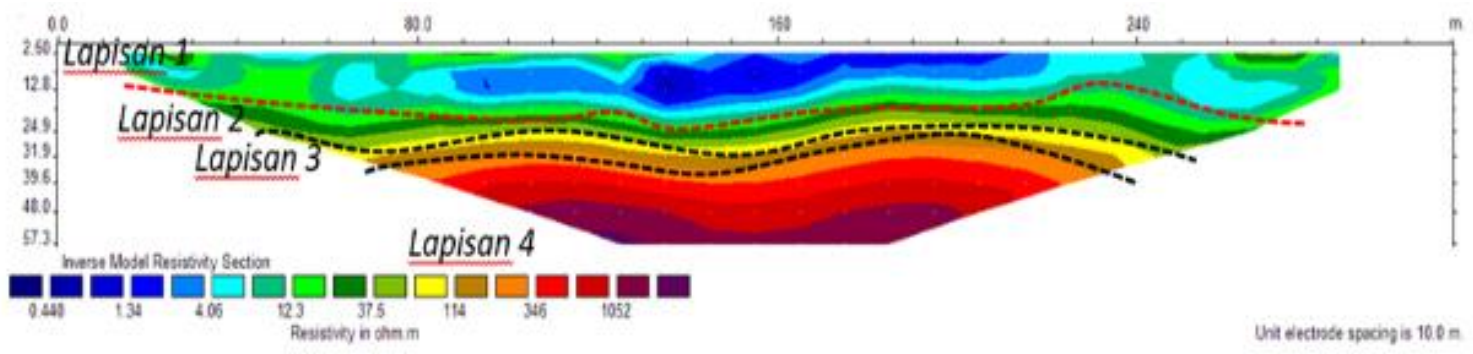

Gambar 4. Profil Geolistrik yang dilakukan pada lokasi penelitian pada Gambar. 1

Penentuan Batas Model.

Dalam pemodelan kondisi batas (boundary condition) merupakan komponen utama dalam pembuatan konseptual sistem aliran air tanah. Kondisi batas (boundary) yang dipakai dalam pemodelan ini adalah: Recharge dan River Boundary.

Untuk menentukan besarnya imbuhan (recharge) dari suatu akuifer maka dipakai perhitungan keseimbangan air tanah. Metode perhitungan imbuhan air tanah untuk daerah tropis dengan curah hujan tinggi menggunakan persamaan matematika, Imbuhan air tanah (U) adalah :

$$
\mathrm{U}=\mathrm{P}-(\mathrm{ETr}+\mathrm{Ro})
$$

Dengan:

$$
E T r=\frac{P}{\sqrt{0,9+\frac{P^{2}}{\left(300+25 T m+0,005 T^{3}\right)^{2}}}}
$$

$$
R o=\frac{1,511\left(P^{1,44}\right)}{\left(T m^{1,34}\right)\left(A^{0,0613}\right)}
$$

Sungai yang ada dimanfaatkan sebagai river boundary (Robbin / Chauchy boundary condition). Beberapa data yang diperlukan dalam river boundary yaitu: tinggi muka air sungai, kedalaman sungai, tebal sedimen, konduktansi sedimen dan lebar sungai. Persamaan matematika yang dipakai dalam river boundary pada program visual modflow adalah (Coelho et al., 2017):

$$
\mathrm{C}=(\mathrm{K} . \mathrm{L} . \mathrm{W}) / \mathrm{M}
$$

dengan $\mathrm{C}$ : conductance $\left(\mathrm{L}^{2} \mathrm{~T}^{-1}\right), \quad \mathrm{K}$ : konduktivitas hidrolik $\left(\mathrm{LT}^{-1}\right)$, L: panjang sungai (L), W: lebar sungai (L) dan M: ketebalan sedimen (L) 


\section{Running (Proses Komputasi)}

Persamaan model

numerik menggunakan teknik finite difference berdasarkan hipotesis berkesinambungan dan Hukum Darcy. Dengan menggunakan Hukum Darcy dan Hukum Kekekalan massa, persamaan matematika yang umum untuk aliran air tanah tiga dimensi dijabarkan sebagai berikut (Vallner dan Porman, 2016) :

$\frac{\partial}{\partial x}\left(K_{x x} \frac{\partial h}{\partial x}\right)+\frac{\partial}{\partial y}\left(K_{y y} \frac{\partial h}{\partial y}\right)+\frac{\partial}{\partial z}\left(K_{z z} \frac{\partial h}{\partial z}\right)-W=S_{s} \frac{\partial h}{\partial t}$

Dengan: $\mathrm{x}, \mathrm{y}, \mathrm{z}$ : cartesian coordinates (L), $\mathrm{K}_{\mathrm{xx}}, \mathrm{K}_{\mathrm{yy}}, \mathrm{K}_{\mathrm{zz}}$ : Nilai Konduktivitas hidraulik (L/T) sepanjang sumbu $\mathrm{x}, \mathrm{y}$, dan $\mathrm{z}$.

$\mathrm{h}$ : Ketinggian piezometric / Head / muka air tanah (L), W: Flux per unit volume $\left(\mathrm{T}^{-1}\right), \mathrm{S}_{\mathrm{s}}$ : Specific storage coefficient $\left(\mathrm{L}^{-1}\right)$, $\mathrm{t}$ : waktu (T).

\section{HASIL DAN PEMBAHASAN}

Proses komputasi dilakukan dalam kondisi steady state flow, yaitu komputasi tidak berubah terhadap perubahan waktu. Hasil model steady state flow digunakan sebagai kondisi awal (initial condition) dari model lokasi penelitian sebelum dilakukan simulasi dari dampak penggunaan air tanah, intrusi air laut atau penyebaran polutan dengan proses komputasi pada aplikasi Visual Modflow dengan cara transient.
Kalibrasi dan Verifikasi

Proses komputasi awal menghasilkan model aliran air tanah yang akan berbeda dari hasil yang diukur (observed) tinggi muka air tanahnya. Kalibrasi model bertujuan agar hasil model bernilai sama dengan pengukuran yang dilakukan di lokasi penelitian (calculated vs observed). Dalam pembuatan pemodelan aliran air tanah yang akan menjadi titik acuan adalah tinggi muka air tanah ( $m d p l)$ (Baalousha, 2008). Perubahan parameter yang dilakukan dalam kalibrasi pemodelan aliran air tanah (Barnett et al., 2012) adalah: perubahan nilai konduktivitas hidraulika (K) pada beberapa atau/dan keseluruhan dari sebaran dan lapisan batuan dan perubahan dengan menyesuaikan nilai imbuhan (recharge) air tanah pada daerah tertentu.

Model dikalibrasi menggunakan a statistical calibration evaluation yang disarankan oleh (Anderson dan Woessner, 1992; Sahoo dan Jha, 2017), dengan menggunakan beberapa kriteria: average residual error, absolute average error, root mean square (RMS), dan normalized root mean square (NRMS). Model ditetapkan sudah menghasilkan kalibrasi yang baik apabila normalized RMS bernilai di bawah dari

$10 \%$.

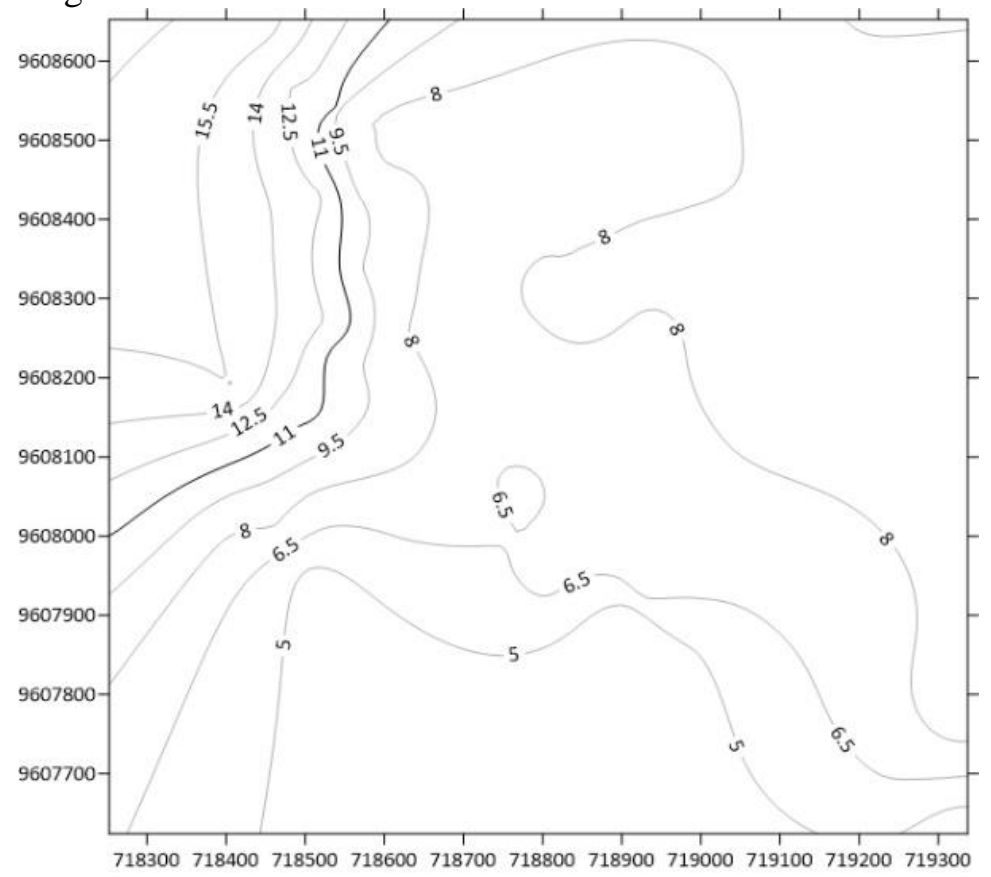

Gambar 5. Kontur Tinggi Muka Air Tanah Hasil Interpolasi 74 Titik Sumur Pengamatan (observed), koordinat 74 titik berada pada Gambar 1. 


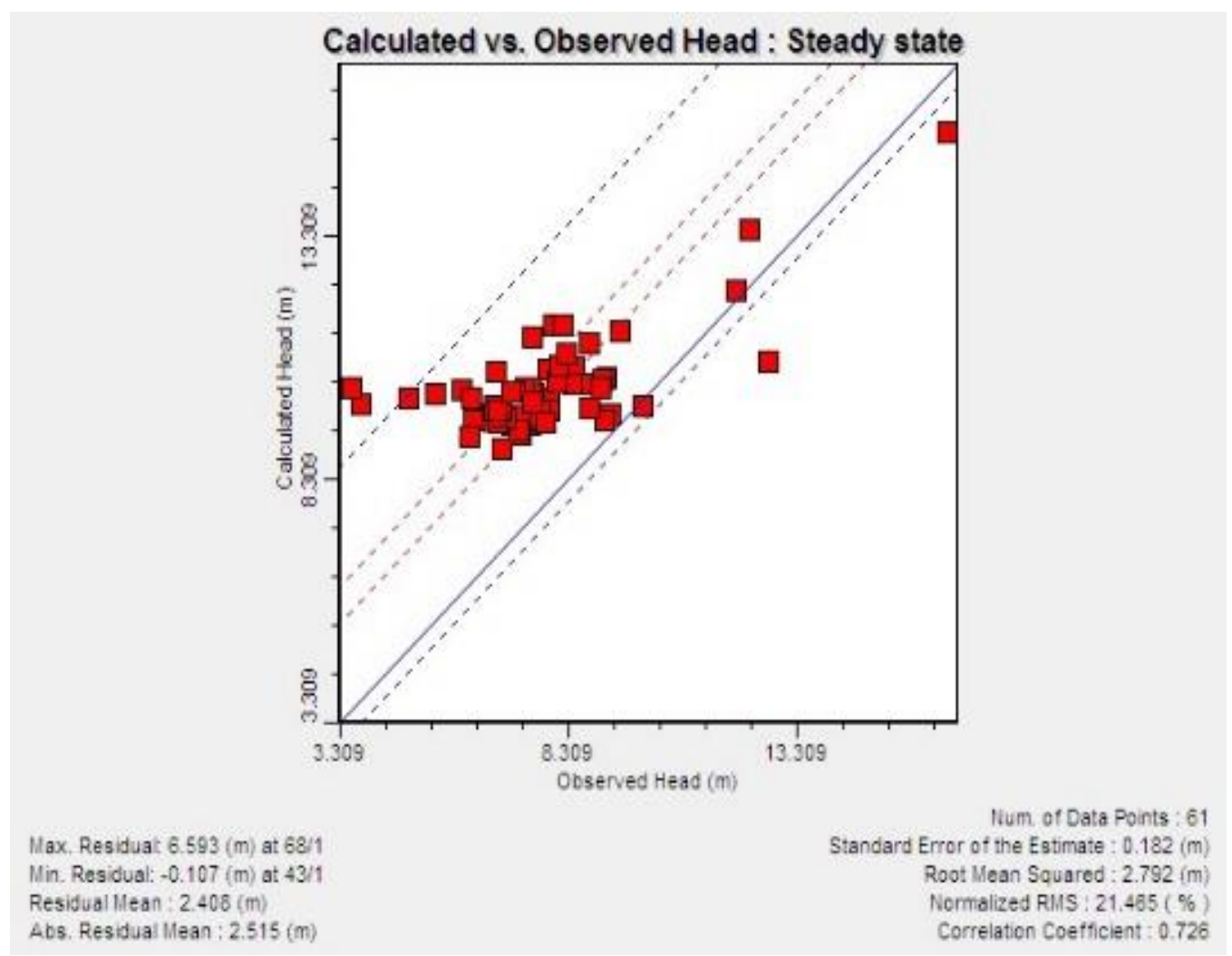

Gambar 6. Grafik nilai perbandingan antara tinggi muka air tanah pada model dan tinggi muka air tanah pada lokasi penelitian (calculated vs observed).

Hasil Kalibrasi/Validasi Model.

Kalibrasi akhir dari model memiliki nilai Standard Error of the Estimate (SEE) sebesar 0,182 meter, nilai Root Mean Squared (RMS) sebesar 2,792 meter, Normalized RMS sebesar 21,465\%, dan Correlation Coefficient sebesar 0,726 . Kalibrasi ini memiliki perbandingan kontur muka airtanah terhitung dan terukur (calculated vs observed) yang jauh lebih baik dari beberapa proses kalibrasi sebelumnya.

Karakteristik akuifer.

Hasil dari model dengan kalibrasi pada lokasi penelitian dibedakan menjadi 5 unit hidrogeologi yang masing-masing memiliki nilai konduktivitas hidraulik yang berbeda untuk beberapa sebaran dan lapisan batuan. Satuan hidrogeologi ini meliputi tiga akuifer dan sebuah akuitar yang kemudian diasumsikan sebagai dari sistem semi akuifer tertekan pada lokasi penelitian.

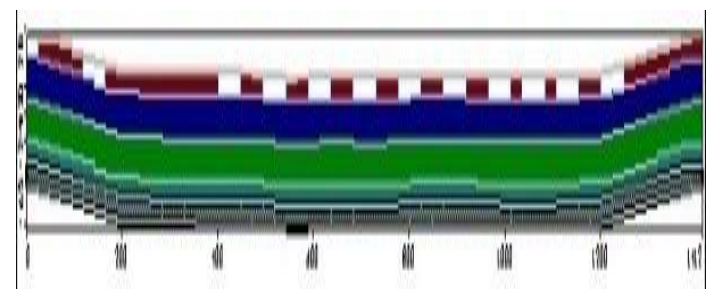

a) Penampang horizontal

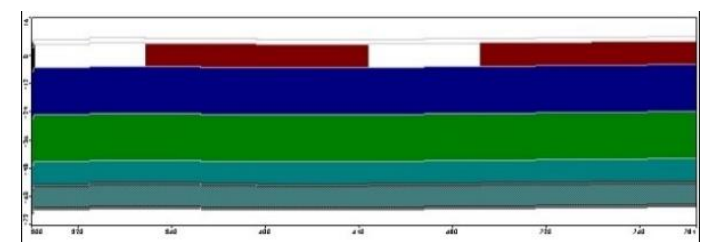

b) Penampang vertikal

Gambar 7. Ketebalan dan sebaran batuan pada hasil model akhir.

Akuifer pertama tersusun atas endapan pasir yang terdapat sisipan material lempung ( $\mathrm{K}=40 \mathrm{~mm} / \mathrm{hari}$ ), Akuifer kedua tersusun atas endapan pasir sedang ke halus $(\mathrm{K}=25$ $\mathrm{m} / \mathrm{hari}$ ) dan akuifer ketiga berupa pasir, gamping dan keriki ( $\mathrm{K}=25-50 \mathrm{~m} / \mathrm{hari})$ yang terhubung dengan dua akuifer sebelumnya.. 


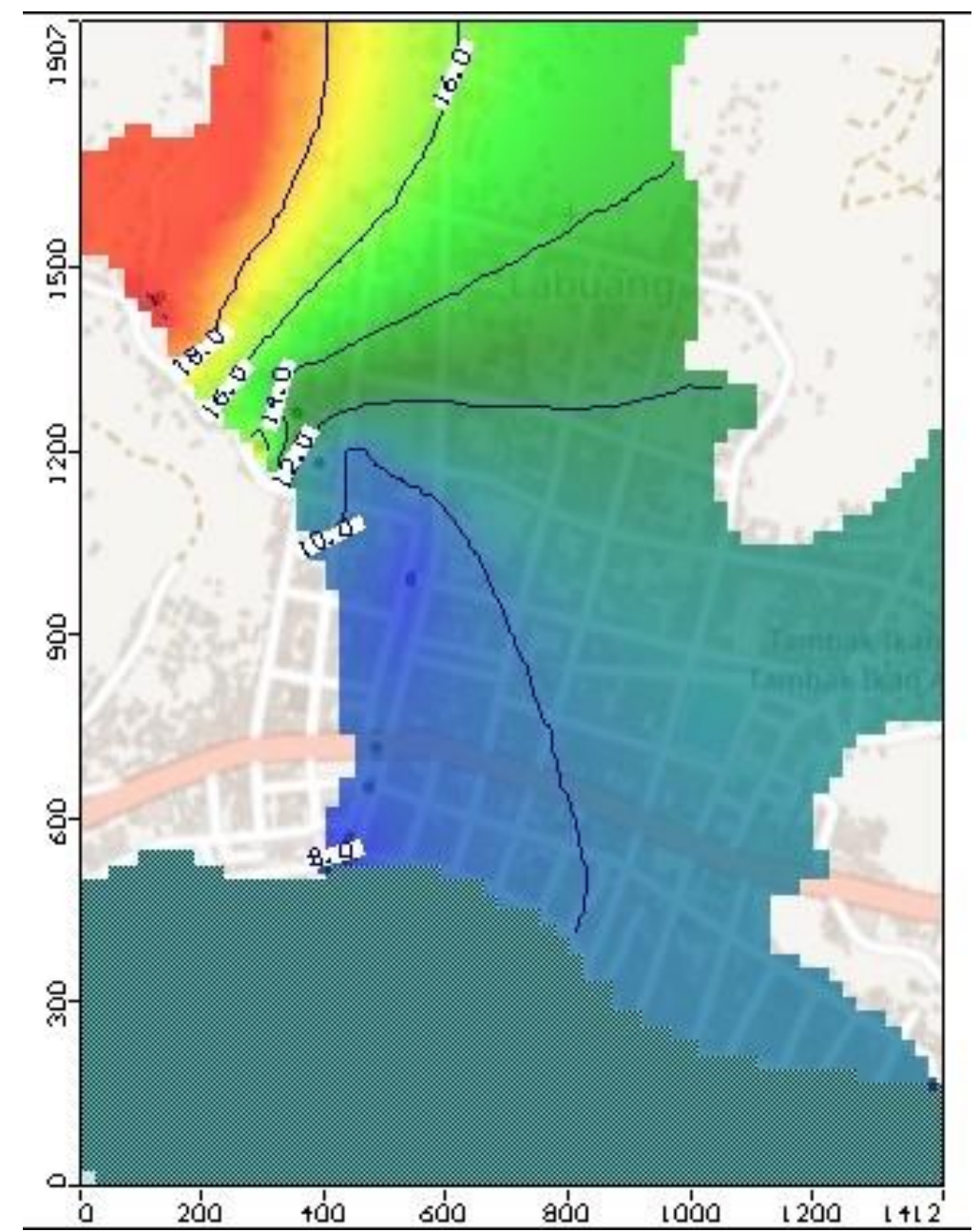

Gambar 8. Ketinggian muka air tanah hasil dari pemodelan (calculated).

\section{SIMPULAN}

Berdasarkan hasil penelitian dan analisis data yang telah dilakukan disimpulkan beberapa hal sebagai berikut: Sistem akuifer pada lokasi penelitian tersusun atas lapisan akuifer semi tertekan yang pada bagian atasnya dilapisi oleh lapisan lempung yang berupa sisipan pada berbagai daerah tertentu. Lokasi penelitian memiliki arah aliran air tanah yang cenderung Utara-Selatan menuju ke arah pantai dengan nilai rata-rata imbuhan air tanah sebesar $100 \mathrm{~mm} / \mathrm{tahun}$.

Berdasarkan nila kalibrasi akhir yang diperoleh yang jauh dari nilai NRMS standar di bawah $10 \%$, dari beberapa sumber yang diusahakan (ESDM Provinsi Sulawesi Barat dan berbagai literatur penelitian) belum menemukan adanya penelitian awal dari penelitian seperti ini, mungkin karena disebabkan daerah penelitian bukan merupakan wilayah yang tergolong CAT (dari data-data di pusat) sehingga perlu diusulkan adanya penelitian yang lebih mendalam mengenai nilai-nilai parameter yang berperang andil dalam pemodelan ini, seperti belum adanya data logbor untuk memastikan material jenis akuifer tersebut dan nilai konduktivitas (K) beberapa batuan pada lokasi penelitian yang dapat mewakili pemodelan, begitu pula pada data sungai pada interpolasi tinggi muka air tanah yang diukur pada lokasi penelitian menunjukkan bahwa tinggi muka sungai lebih rendah dari tinggi muka air tanah yang terinterpolasi, sehingga mengasumsikan bahwa air tanah yang mengisi sungai tersebut tetapi pada hasil pemodelan memperlihatkan sebaliknya lebih tinggi dan mengasumsikan air sungai yang mengisi air tanah tersebut sehingga memerlukan adanya data sebelumnya yang menerangkan sejauh mana terintegrasi dengan data-data lainnya. 


\section{UCAPAN TERIMA KASIH}

Penelitian ini didanai oleh Program Hibah dari Kementerian Riset Dikti pada skema program PDP (Penelitian Dosen Pemula), ucapan terima kasih pula atas sumbangsih data-data pendukung dari penelitian dari Dinas Provinsi Energi Sumber Daya dan Mineral Sulawesi Barat serta dukungan dan bantuan Universitas Sulawesi Barat.

\section{DAFTAR PUSTAKA}

Anderson, M. P., dan Woessner, W. W. 1992. Applied Groundwater Modeling: Simulation of Flow and Advective Transport. Elsevier Science.

Baalousha, H. 2008. Fundamentals of Groundwater Modelling. 64(0), 113130.

Bachri, S. 2012. Fase Kompresi Di Selat Makassar Berdasarkan Data Geologi Daratan, Seismik Laut Dan Citra Satelit. Jurnal Sumber Daya Geologi, 22(3), 137-144.

Barnett, B., Townley, L. R., Post, V., Evans, R. E., Hunt, R. J., Peeters, L., Richardson, S., Werner, a. D., Knapton, a., dan Boronkay, a. 2012. Australian Groundwater Modelling Guidelines. In Waterlines Report Series (Waterlines, Issue 82). National Water Commission.

Coelho, C. D., Faria, A. C. S., dan Marques, E. A. G. 2017. Comparative Analysis Of Different Boundary Conditions And Their Influence On Numerical Hydrogeological Modeling Of Palmital Watershed, Southeast Brazil. Journal of Hydrology: Regional Studies, 12 (December2016),210-219.

https://doi.org/10.1016/j.ejrh.2017.05.0 06

Hendrayana, H., dan Putra, D. 2015. Konservasi Airtanah-Sebuah Pemikiran (2008) (Heru Hendrayana \& Doni Prakasa EP) (Issue May). https://doi.org/10.13140/RG.2.1.1760.4 009

Lakshmi, C., dan Narayanan, R. M. 2015. Study on Groundwater Modeling of Aquifers Using Visual Modflow. International Research Journal of Engineering and Technology (IRJET), 2(2), 23-26.
Marwadi, A. 2018. Pemodelan Aliran Airtanah Sub Das Opak Wilayah Kecamatan Umbulharjo, Kota Yogyakarta Daerah Istimewa Yogyakarta. Universitas Pembangunan Nasional" Veteran" Yogyakarta. http://eprints.upnyk.ac.id/id/eprint/169 05

Rejekiningrum, P. 2010. Peluang Pemanfaatan Air Tanah untuk Keberlanjutan Sumber Daya Air. Jurnal Sumberdaya Lahan, 3(2), 85-96.

Sahoo, S., dan Jha, M. K. 2017. Numerical Groundwater-Flow Modeling To Evaluate Potential Effects Of Pumping And Recharge: Implications For Sustainable Groundwater Management In The Mahanadi Delta Region, India. Hydrogeology Journal, 25(8), 24892511. https://doi.org/10.1007/s10040017-1610-4

Sallam, O. M. 2015. Groundwater Modeling To Evaluate Impact of Deep Foundations On Flow In Shallow Aquifers (Case Study: The Holy Mosque Area, Makkah City, KSA). Arabian Journal of Geosciences, 8(7), 5189-5202.

https://doi.org/10.1007/s12517-014$1557-\mathrm{x}$

Sunarwan, B., dan Firmansyah, D. 2016. Tinjauan Kimia Airtanah Kabupaten Majene, Sulawesi Barat. Jurnal Teknologi, Volume I(Edisi 27), 9-15.

Vallner, L., dan Porman, A. 2016. Groundwater Flow and Transport Model of The Estonian Artesian Basin and Its Hydrological Developments. Hydrology Research, 47(4), 814-834. https://doi.org/10.2166/nh.2016.104

Wilopo, W. 2018. Groundwater Flow Modeling In The Wates Coastal Aquifer, Kulon Progo District, Yogyakarta Special Province, Indonesia. International Journal of GEOMATE,14(41),119-125.

Yao, Y. Y., Zheng, C. M., Tian, Y., Liu, J., \& Zheng, Y. 2015. Numerical Modeling of Regional Groundwater Flow in The Heihe River Basin, China: Advances and New Insights. Science China Earth Sciences, 58(1), 3-15. https://doi.org/10.1007/s11430-0145033-y 